\title{
Primary Protection of Reinforced Concrete against Impact of Carbon Dioxide
}

\author{
VALERII MARKAZOVICH LATYPOV, ASKAR RAMILEVICH ANVAROV, \\ EKATERINA VALERIEVNA LUTSYK, PAVEL ANATOLIEVICH FEDOROV and \\ TATIANA VLADIMIROVNA LATYPOVA
}

Ufa State Petroleum Technological University, Kosmonavtov St., Ufa, 450062, Russia.

http://dx.doi.org/10.13005/ojc/310132

(Received: October 06, 2014; Accepted: November 20, 2014)

\begin{abstract}
Provision of reliability of structures is an important issue at the designing stage. One of reliability aspects is durability. In order to estimate the durability of reinforced concrete it is required to apply standard procedure of calculation which, according to SNIP Regulations 2.03.11-85 Protection of Engineering Structures against Corrosion, can be implemented with the use of means of primary and secondary protection ${ }^{1}$. A peculiar feature of buildings with built-up or monolithic framework is that the major portion of reinforced concrete items remains in the structure of multi-layer walls and cannot be reached for renewal of the means of secondary protection. That is, in order to provide durability of structures it is possible to rely only on the means of primary protection. The article discusses estimations of parameters of concrete protective layer (its thickness and density), based in numerical solution of differential equations, which describe carbonization and guarantee protection of reinforcement against corrosion for the design operation lifetime of structure.
\end{abstract}

Key words: Reinforced concrete, carbon dioxide, structures.

\section{INTRODUCTION}

\section{Mathematical simulation of concrete} carbonization

Durability of reinforced concrete within corrosion impact of environment can be conditionally subdivided into two periods (Fig. 1):

$$
T=t_{1}+t_{2}
$$

However, in fact only the time period as $t_{1}$ should be reasonably considered as durability $\mathrm{T}$ (before initiation of reinforcement corrosion), that is, the time period $t_{2}$, should be neglected, since the error of determination of the time period $t_{2}$ can be very high.

Exactly this approach is used by numerous researchers ${ }^{1,2,4,8}$, though attempts of more or less 
reliable determination of the time period $t_{2}$ are already under way [12]. Up till now there are no standard procedures of calculation of the time period $t_{1}$, which determines the urgent character of investigation into this problem. Indeed, the depth of concrete damage as a function of operation lifetime should serve as a basis for solution adoption both within designing of new projects, and within estimation of existing structures. Since the existence of reinforced concrete is possible only with existence of protective layer $a_{p}$ and cohesion of reinforcement with concrete, then the most convenient way to determine the time period $t_{1}$ by functional

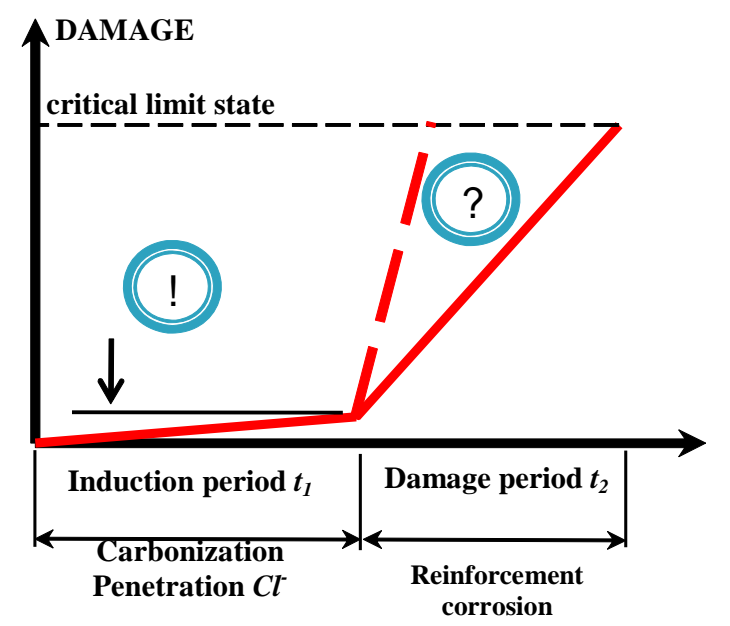

Fig. 1. Schematic view of damage within steel corrosion in concrete ${ }^{1}$ dependence of the damage depth $L=f(t)$ upon the condition $L<O_{p}$.

It is obvious that the final purpose of development of mathematical model of corrosion $L=f(t)$ is the obtaining of simple equation suitable for engineering calculations. Corrosion of concrete is related with interaction between polymineral cement stone and multi-component ambient medium. However, almost all researchers within development of equation $L=f(t)$ aiming at simplification proceed form the interaction only between two substances. Mathematical model of physico-chemical interaction between two substances has long been known: these are differential equations of the second order in partial derivatives, which simultaneously includes diffusion, dissolution and chemical interaction between two components: the component, which is the ambient medium, and the component, which is soluble components of cement stone (in the case of corrosion of concrete), with slow or fast reaction rate (Fig. 2; Table 1, Eq. (2)).

For most simple cases (instant reaction or reaction does not occur) the process is determined only by diffusion (Fig. 2; Table 1, Eq. (3)).

Until recently the bottleneck of all models was obtaining of simple engineering equation

Table 1.

\begin{tabular}{|c|c|c|c|}
\hline $\begin{array}{l}\text { Variant of } \\
\text { interaction } \\
\text { between } \\
\text { substance } \\
\text { ? and? } \\
\text { (Fig. 2) }\end{array}$ & $\begin{array}{l}\text { Examples of } \\
\text { interaction between } \\
\text { concrete and } \\
\text { diffusing ambient } \\
\text { medium }\end{array}$ & Process description & $\begin{array}{l}\text { Differential equations describing the } \\
\text { process }\end{array}$ \\
\hline 2 and 3 & $\begin{array}{l}\text { Contact between } \\
\text { cement stone and } \\
\text { solutions of salts, } \\
\text { acids, etc. }\end{array}$ & $\begin{array}{l}\text { Existence of chemical } \\
\text { interaction between } \\
\text { cement and ambient } \\
\text { medium, the process is } \\
\text { controlled by diffusion } \\
\text { and chemical reaction }\end{array}$ & 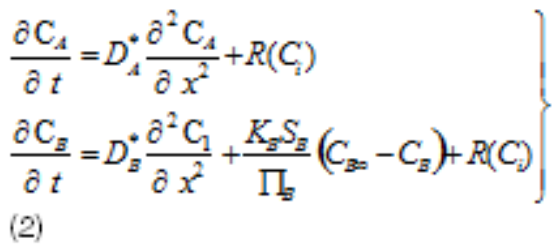 \\
\hline 1 & $\begin{array}{l}\text { Contact between } \\
\text { cement stone and } \\
\text { chlorides }\end{array}$ & $\begin{array}{l}\text { No chemical interaction } \\
\text { between concrete and } \\
\text { ambient medium, the } \\
\text { process is controlled } \\
\text { by diffusion }\end{array}$ & $\frac{\partial C_{A}}{\partial t}=D_{A}^{*} \frac{\partial^{2} C_{A}}{\partial x^{2}}$ \\
\hline
\end{tabular}


derived from the set (2). Numerous researchers simplified the equation assuming $R_{i}(C) \sim 0$, thus transferring to Eq. (3), also known as the Fick's second law. At the same time Eq. (3) has analytical solution in the form of common in the field of concrete durability square-root-of-time law:

where $L$ is the concrete neutralization depth, $\mathrm{mm}, t$ is the operation lifetime, years, $A$ is the coefficient depending on the concentration of carbon dioxide $c$, the effective diffusion coefficient D' and concrete reaction capacity $m_{0}$.
Mathematical models, based on these principles and developed by Russian and foreign researchers (S.N. Alekseev [1], V.G., E.A. Guzeev [3], B.V. Gusev [4], T.K. Dement'ev [6], F.M. Ivanov [7], V.M. Moskvin [8], A.F. Polak [8], Sh.M. Rahimbaev [13], N.K. Rozental' [14], V.F. Stepanova [4], A.S. Fai'vusovich [4], V.V. Iakovlev [10], H.I. Wiering [24], V.G. Papadakis [19], M. Liang [18], T. Ishida [17], Younsi [16]), can be finally expressed similar to Eq. (4).

These models were obtained by experimental processing of the results of on-site investigations, laboratory experiments and applied

Table 3. Coefficient $A_{p}$ (cm per year ${ }^{-1 / 3}$ ) as a function of concrete density (WI C) and operation mode of structure

\begin{tabular}{llll}
\hline $\begin{array}{l}\text { Water to cement } \\
\text { ratio WIC }\end{array}$ & $\begin{array}{l}\text { Waterproofing } \\
\text { brand } \mathbf{W}\end{array}$ & $\begin{array}{l}\text { Normal } \\
\text { operation mode }\end{array}$ & $\begin{array}{l}\text { Value of } \mathrm{A}_{\mathrm{p}} \\
\text { Wet operation } \\
\text { mode }\end{array}$ \\
\hline 0.65 & 2 & 1.026 & 0.51 \\
0.55 & 4 & 0.682 & 0.25 \\
0.5 & 6 & $0.51 A_{2} \sqrt{t}$ & 0.12 \\
0.43 & 8 & 0.2692 & - \\
0.4 & 10 & 0.166 & \\
0.38 & 12 & 0.0972 & \\
0.35 & 14 & - & \\
\hline
\end{tabular}

Table 2.

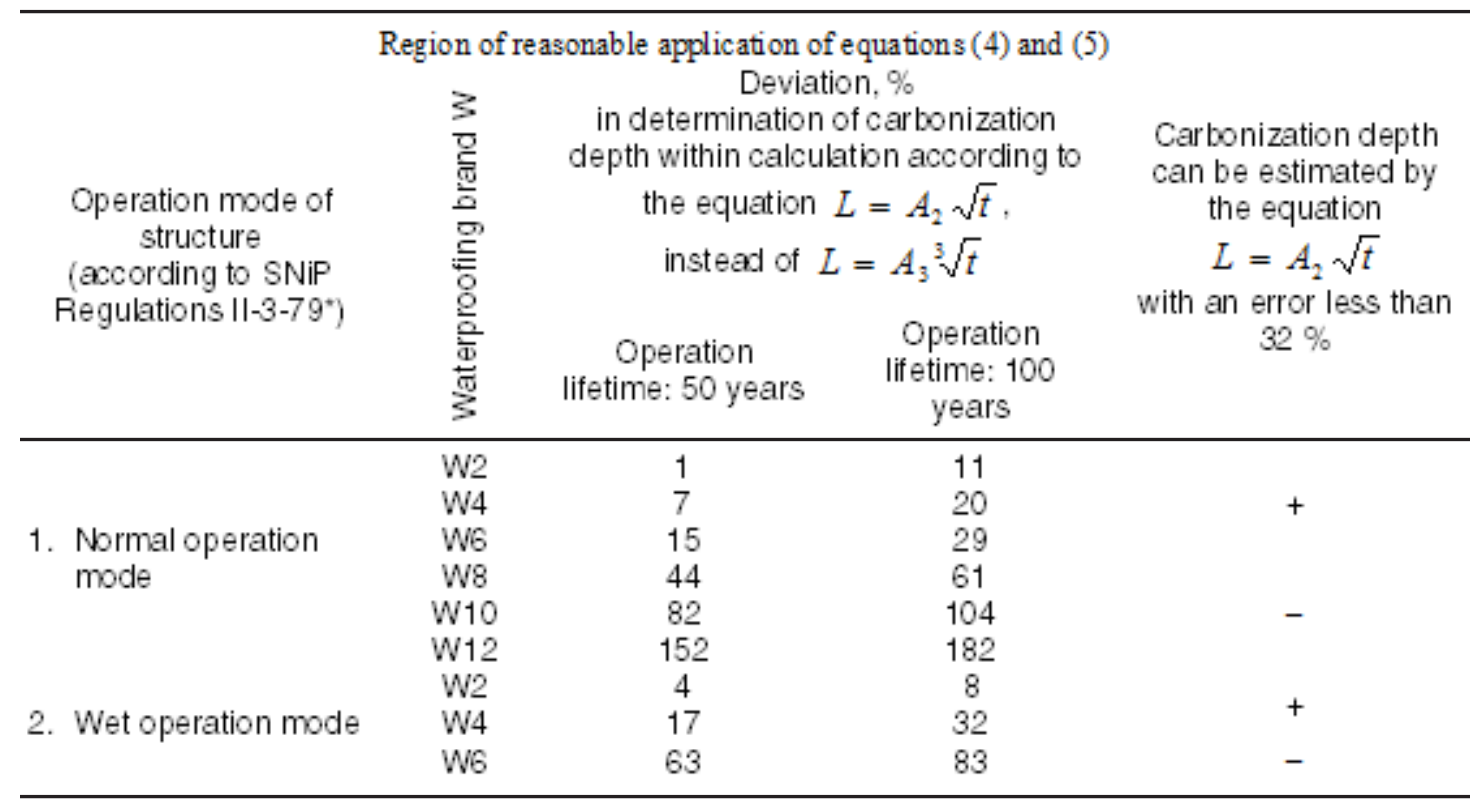


mathematical software. The developed models of the type: $L=f(x)$ can be subdivided into two lines [5]: the first line is applied together with the mass transfer equations for description of kinetics of physico-chemical processes (and is more common); the second line involves dependences of thermodynamic equilibrium.

The drawbacks of the first line consist of mathematical assumptions and simplifications, which influence on the accuracy of calculations. The drawbacks of the second line involve deviations from the results of on-line and laboratory experiments, awkwardness of calculations, numerous coefficients, determination of which requires for development of dedicated procedures.

In general, most cases are reduced to classical solution, known as the already mentioned square-root-of-time law (4).
In Russia the most significant contribution into development of calculation methods of provision of reinforced concrete durability was made by Prof. A. F. Polak in the 1970s-1980s by means of quasi-stationary mode and subdivision of corroding layer into areas. Despite the fact that the obtained by Prof. Polak equation for determination of the penetration depth of ambient medium into cement stone accounted for numerous process variables, it still remained one of variants of the square-root-of-time law. Mathematical model of the type (4) is based on the solution of differential equations describing various physical and chemical processes of corrosion. However, these solutions were obtained on the basis of several assumptions and this could result in decreased accuracy of the results. One of non-considered in model (4) processes is chemical interaction between ambient medium and soluble components of cement stone, which leads to underestimation of penetration rate

\begin{tabular}{|c|c|c|c|}
\hline \multicolumn{4}{|c|}{ The influence of irreversible reaction } \\
\hline $\begin{array}{l}\text { a) reaction does not } \\
\text { occur }\end{array}$ & b) slow reaction & c) fast reaction & d) instant reaction \\
\hline \multicolumn{4}{|c|}{ The process is controlled by } \\
\hline diffusion & \multicolumn{2}{|c|}{ diffusion and chemical reaction } & diffusion \\
\hline$\uparrow$ & $\uparrow$, & $\uparrow$, & $\nabla$ \\
\hline$\nabla$ & $\nabla$. & & $\nabla$ \\
\hline 0 & & & 0 \\
\hline
\end{tabular}

Fig. 2. Types of curves characterizing the concentration distribution within bimolecular reaction of the following type: $\grave{A}+\hat{A} Z ̌$ products [15] Note: $\tilde{o}=\tilde{o}_{1}-$ coordinate of reaction plane

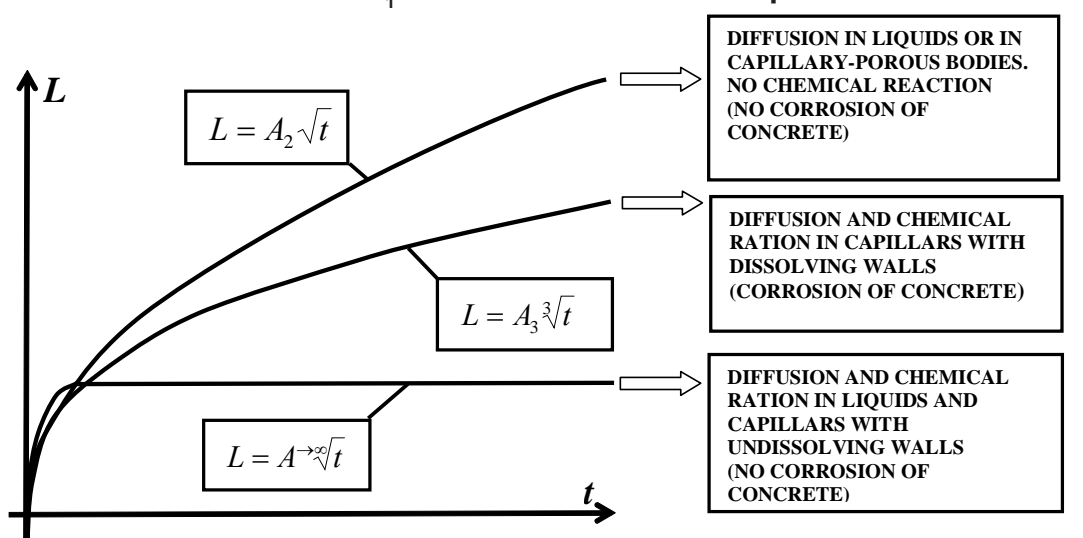

Fig. 3. Distribution pattern $L=f(t)$ with consideration for development and updating of mathematical model of the process 


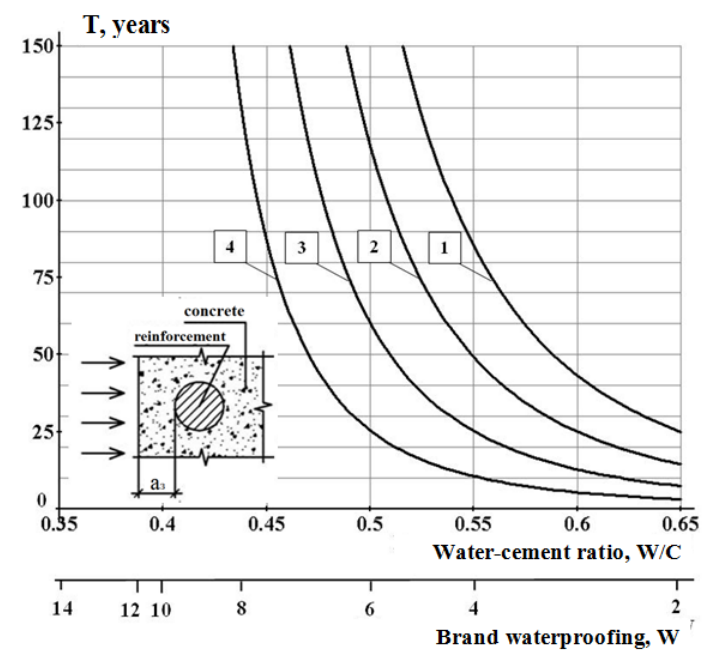

Fig. 4. Operation lifetime of structure $T$ as a function of waterproofing brand $\mathrm{W}$ under normal operation modes at thickness of protective concrete layer: $1-a_{p}=30 \mathrm{~mm} ; 2-a_{p}$ $=25 \mathrm{~mm} ; 3-a_{p}=20 \mathrm{~mm} ; 4-a_{p}=15 \mathrm{~mm}$

of aggressive medium into concrete. Consideration of this process can significantly influence on the type of developed calculation dependence $L=f(t)$ (Fig. 3), which is also mentioned in [13].

\section{Results of numerical experiment}

We developed and made adjustment of the existing equation of the type (4) by calculation experiment using computer-aided symbolic (analytical) simulation, namely, development of mathematical model based on numerical solution of differential equations combining actually all variables of corrosion (Fig. 3).

The results of numerical experiment make it possible to conclude that within expressed chemical interaction between ambient medium and soluble components of cement stone the mathematical model of concrete corrosion can be as follows:

The obtained calculated data (Table 2) confirm applicability of dependence of the type $L=A_{2} \sqrt{t}$ to concretes of high waterproofing with relatively low design or actual operation lifetime.
Designing of durability of structures made of concrete brands W6 and higher for long-term operation should be reasonably based on equation $L=A_{3} \sqrt[3]{t}$.

Based on the data of inspection of technical state of concrete and reinforced concrete structures carried out on several hundreds of facilities with various operation modes the values $A_{p}$ were determined (Table 3 ) as a function of concrete density and temperature-humidity conditions of structure operation, when concrete corrosion occurs under so-called regular conditions of operation and reinforcement corrosion is caused by carbonization of concrete protective layer.

\section{CONCLUSIONS}

Therefore, at the stage of designing of structures the obtaining of rated operation lifetime under regular operation conditions (that is, under impact of carbon dioxide and moisture) can be provided only by means of the primary protection selection of thickness of protective layer $a_{p}$, as well as concrete- waterproofing brand W (Fig. 4). For

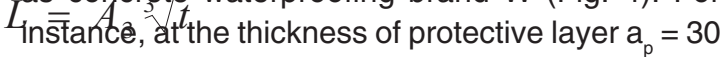
$\mathrm{mm}$ the rated operation lifetime $T_{r}=100$ years can be provided by regular concrete of W4 brand, and if $a_{p}=15 \mathrm{~mm}$, then the rated lifetime $T_{r}=100$ years can be achieved without means of secondary protection only by application of concrete of extremely low waterproofing brand of at least W8.

At present the companies of building industry have all the things needed for provision of required concrete brand in terms waterproofing and strict supervision of thickness of concrete layer, thus investors, customers, designers and constructors can be assured of capabilities of implementation of project design concerning achievement of design durability of reinforced concrete structures of various purposes.

\section{ACKNOWLEDGMENTS}

This work was supported by Ministry of Education of Russia in the scope of Federal program No. 2014/241. Research Project No. 2093. 


\section{REFERENCES}

1. S. N. Alekseev, F. M. Ivanov, C. Modry, and P. Shissl. Durability of reinforced concrete in aggressive mediums. Moscow, Stroiizdat, 1990.

2. S. N. Alekseev and N. K. Rozental. Corrosion resistance of reinforced structures in aggressive industrial medium. Moscow, Stroiizdat, 1976.

3. Guzeev E. A., Alekseev S.N., and Savitskii N. V. Consideration of aggressive impacts in the design regulations for structures. Beton and Zhelezobeton, 1992, No. 10.

4. B. V. Gusev, A. S. Faivusovich, and V. F. Stepanova, et al. Mathematical models of corrosion of concrete. Moscow, TIMR Publishing House, 1996.

5. B. V. Gusev and A. S. Faivusovich. Mathematical model of atmospheric corrosion of concretes with consideration for phase transitions. Collection of articles, Analytical solution ... PP. $55-62$

6. Dementiev G. K. Conditions of concrete stability in mineralized waters. Neftianoe hoziaistvo. 1929, No. 9.

7. Ivanov F. M. On simulation of concrete corrosion. Beton i zhelezobeton. 1982, No. 7.

8. Moskvin, V. M. Concrete corrosion. Moscow: State publishing house for construction and architecture, 1952.

9. A. F. Polak, Simulation of corrosion of reinforced concrete and forecasting of its durability. Itogi nauki i tekhniki. Corrosion and protection against corrosion. Vol. XI. Moscow: VINITI, 1986. PP. 136-180.

10. Polak A. F., Habibullin R. G., Yakovlev V.V., and Latypov V. M. Generalized mathematical model of concrete corrosion in aggressive liquid mediums. Beton i zhelezobeton. 1981, No. 9.

11. Polyanin, A. D. Guidebook on linear equations of mathematical physics. Moscow: Fizmatlit, 2001.

12. A. A. Prokopovich. Flexural resistance of reinforced structures with various conditions of cohesion of longitudinal reinforcement with concrete. Samara: NVF. Sensors. Modules.
Systems, 2000.

13. Rakhimbaev Sh. M. and Avershina N. M. Forecasting of durability of building materials by single test time. Stroitelnye materialy. 1994, No. 4.

14. N. K. Rozental'. Corrosion resistance of cement blocks of low and extremely low waterproofing. Moscow: Center of Design Products, 2006.

15. Thomas K. Sherwood, Robert L. Pigford, and Charles R. Wilke. Mass transfer, McGraw-Hill Book Company (1975).

16. Younsi, Ph. Turcry, A. Aït-Mokhtar, and S. Staquet. Accelerated carbonation of concrete with high content of mineral additions: Effect of interactions between hydration and drying.

17. T. Ishida, K. Maekawa, and M. Soltani. Theoretically Identified Strong Coupling of Carbonation Rate and Thermodynamic Moisture States in Micropores of Concrete. Journal of Advanced Concrete Technology Vol. 2, No. 2, PP.213-222, June 2004. Copyright (C) 2004 Japan Concrete Institute

18. Liang, M., Wu, J., and Liang, C. (2001). Multiple Layer Fuzzy Evaluation for Existing Reinforced Concrete Bridges. J. Infrastruct. Syst., 7(4), 144-159.

19. V.G. Papadakis, C.G. Vayenas, and M.N. Fardis, A reaction engineering approach to the problem of concrete carbonation, Journal of the American Institute of Chemical Engineers, 1 (11), 1989, 110-122.

20. Y. Shao, S. Monkman, and A. J. Boyd Recycling carbon dioxide into concrete: a feasibility study / Concrete Sustainability Conference. - National Ready Concrete Association, 2010 - PP. 1-10

21. M.M.Y. Delmi, Étude de l'hydratation et du couplage carbonatationéchanges hydriques dans les mortiers et bétons, Thèse de Doctorat de l'Université de La Rochelle, 2004.

22. History of Cement Static Content [webresource]/http://www.cement.ca/en/content/ History of Cement Static Content.html

23. International Energy Statistics [webresource] http://www.eia.gov/cfapps/

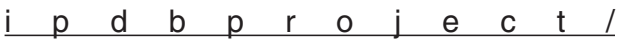


iedindex3.cfm?tid $=90 \&$ pid $=44 \&$ aid $=8$ $>1=>2$;. 11.10 .2013

24. Wiering H.J. Longtime Studies on the Carbonation of Concrete under Normal Outdoor Exposure/RILEM - Seminar "Durability of Concrete Structures Under Normal Out-door Conditions», Hannover,
1984, PP.104-108.

25. A. R. Anvarov, P. A. Fedorov, T. V. Latypova, E.V. Lutsyk, T.Z. Gilmutdinov, and V. M. Latypov . Carbonization of concrete: worried about durability? //The 5th Asia Conference on Earthquake Engineering(5ACEE), October 16-18, 2014, Taipei, Taiwan 